\title{
Airway pressure and transpulmonary pressure during high-frequency oscillation for acute respiratory distress syndrome
}

\author{
William R Henderson MD ${ }^{1,2}$, Paolo B Dominelli $\mathrm{MSc}^{2}$, Donald EG Griesdale MD MPH${ }^{1}$, \\ Daniel Talmor $\mathrm{MD}^{3}$, A William Sheel $\mathrm{PhD}^{2}$
}

WR Henderson, PB Dominelli, DEG Griesdale, D Talmor, AW Sheel. Airway pressure and transpulmonary pressure during high-frequency oscillation for acute respiratory distress syndrome. Can Respir J 2014;21(2):107-111.

BACKGROUND: High-frequency oscillation (HFO) is used for the treatment of refractory hypoxic respiratory failure.

OBJECTIVE: To demonstrate that the mean transpulmonary pressure $\left(\mathrm{P}_{\mathrm{L}}\right)$ cannot be inferred from mean airway pressure (mPaw).

METHODS: In seven patients already undergoing HFO for refractory acute respiratory distress syndrome, esophageal pressure (Pes) was measured using an esophageal balloon catheter. Pleural pressure $(\mathrm{Ppl})$ and $\mathrm{P}_{\mathrm{L}}$ were calculated from Pes.

MAIN RESULTS: In the seven patients (mean [ \pm SD] age $59 \pm 9$ years) treated with $\mathrm{HFO}$ at $5 \pm 1 \mathrm{~Hz}$ and amplitude $75 \pm 10 \mathrm{cmH}_{2} \mathrm{O}$, the mPaw was $27 \pm 6 \mathrm{cmH}_{2} \mathrm{O}$, Ppl was $9 \pm 6 \mathrm{cmH}_{2} \mathrm{O}$ and $\mathrm{P}_{\mathrm{L}}$ was $18 \pm 11 \mathrm{cmH}_{2} \mathrm{O}$. Successful catheter placement and measurement of Pes occurred in $100 \%$ of subjects. There was no correlation between $\mathrm{P}_{\mathrm{L}}$ and $\mathrm{mPaw}$. The majority of subjects required hemodynamic support during the use of HFO; the frequency and degree of support during the study period was no different than that before the study.

CONCLUSION: The present report is the first to describe measuring Pes and calculating Ppl during HFO for acute respiratory distress syndrome. While both current guidelines and recent trials have titrated treatment based on $\mathrm{mPaw}$ and oxygenation, there is wide variability in $\mathrm{P}_{\mathrm{L}}$ during $\mathrm{HFO}$ and $\mathrm{P}_{\mathrm{L}}$ cannot be predicted from mPaw.

Key words: Adult; Critical care; High-frequency oscillation; Lung; Mechanical ventilation; Pneumonia

$\mathrm{H}$ ypoxic respiratory failure and acute respiratory distress syndrome (ARDS) are common reasons for mechanical ventilation in critically ill patients. Although causation varies, ARDS is currently defined as severe hypoxia (partial pressure of oxygen $\left[\mathrm{PaO}_{2}\right] /$ fraction of inspired oxygen $\left[\mathrm{FiO}_{2}\right]$ ratio $<300$ ) within one week of a known clinical insult, new or worsening hypoxia not due to left heart failure, and bilateral opacifications on chest $\mathrm{x}$-ray (1).

Recent advances in clinical practice have focused on minimizing ventilator-induced lung injury (VILI) by minimizing tidal volume $\left(\mathrm{V}_{\mathrm{T}}\right)$ and alveolar pressure $\left(\mathrm{P}_{\mathrm{A}}\right)$. The ARDS Network trial of low $\mathrm{V}_{\mathrm{T}}$ ventilation demonstrated that $\mathrm{V}_{\mathrm{T}}<6 \mathrm{~mL} / \mathrm{kg}$ and end-inspiratory plateau airway pressure (Pplat) $<30 \mathrm{cmH}_{2} \mathrm{O}$ may decrease absolute mortality by almost $9 \%(2)$.

High-frequency oscillation (HFO) is a novel form of ventilation that is increasingly used for the treatment of refractory hypoxic respiratory failure resulting from acute lung injury or ARDS, and provides many of the benefits of lung-protective ventilation gained with a low $\mathrm{V}_{\mathrm{T}}$ strategy (3). HFO delivers $\mathrm{V}_{\mathrm{T}}$ as little as $23 \mathrm{~mL}$ to $225 \mathrm{~mL}$ (often smaller than dead space) using higher mean airway pressure (mPaw) than conventional mechanical ventilation $(\mathrm{CMV})$ and frequencies from $3 \mathrm{~Hz}$ to $10 \mathrm{~Hz}$ (4). Although some investigators have attempted
La pression des voies aériennes et la pression transpulmonaire pendant l'oscillation à haute fréquence pour soigner le syndrome de détresse respiratoire aiguë

HISTORIQUE : L'oscillation à haute fréquence (OHF) est utilisée pour traiter l'insuffisance respiratoire hypoxique réfractaire.

OBJECTIF : Démontrer qu'on ne peut pas inférer la pression transpulmonaire moyenne $(\mathrm{Pm})$ à partir la pression moyenne des voies aériennes (Pmva).

MÉTHODOLOGIE : Chez sept patients qui subissent déjà une OHF en raison d'un syndrome de détresse respiratoire aiguë réfractaire, la pression œsophagienne (Pœ) a été mesurée à l'aide d'un cathéter à ballonnet œsophagien. La pression pleurale $(\mathrm{Ppl})$ et la $\mathrm{Pm}$ ont été calculées à partir de la Pœ.

PRINCIPAUX RÉSULTATS : Chez les sept patients (moyenne [ \pm ÉT] de $59 \pm 9$ ans) traités par OHF à $5 \pm 1 \mathrm{~Hz}$ et à une amplitude de $75 \pm 10 \mathrm{~cm}$ d'eau, la Pmva s'élevait à $27 \pm 6 \mathrm{~cm}$ d'eau, la Pplà $9 \pm 6 \mathrm{~cm}$ d'eau et la TP à $18 \pm 11 \mathrm{~cm}$ d'eau. On a pu installer le cathéter et mesurer la Pœ chez 100 \% des sujets. Il n'y avait pas de corrélation entre la Pmet la Pmva. La majorité des sujets avaient besoin d'un soutien hémodynamique pendant l'utilisation de l'OHF. La fréquence et le degré de soutien pendant la période de l'étude ne différaient pas d'avant l'étude.

CONCLUSION : Le présent rapport est le premier à décrire la mesure de la Pœe et le calcul de la Ppl pendant une OHF pour soigner un syndrome de détresse respiratoire aiguë. Bien que, selon les lignes directrices actuelles et dans les récents essais, le traitement était titré d'après la Pmva et l'oxygénation, on constate une grande variabilité de la Pm pendant l'OHF, et on ne peut prédire la $\mathrm{Pm}$ à partir de la Pmva.

to infer appropriate mPaw during HFO from analysis of pressurevolume curves (5), this analysis rarely occurs in clinical practice. Rather, mPaw is determined empirically, usually by setting it at $3 \mathrm{cmH}_{2} \mathrm{O}$ to $5 \mathrm{cmH}_{2} \mathrm{O}$ higher than the mPaw generated during CMV. Despite the known lack of relationship between airway pressure (Paw) and transpulmonary pressure $\left(\mathrm{P}_{\mathrm{L}}\right)$ during $\mathrm{CMV}$, no attempts have been made to determine $\mathrm{P}_{\mathrm{L}}$ during $\mathrm{HFO}$. In fact, current guidelines and two recent large clinical trials of $\mathrm{HFO}$ titrate ventilator management to mPaw rather than $P_{L}(6-8)$. The goal of the present study was to demonstrate the feasibility of esophageal manometer placement during $\mathrm{HFO}$ and to obtain measurements of esophageal pressure (Pes), thereby estimating pleural pressure $(\mathrm{Ppl})$ and $\mathrm{P}_{\mathrm{L}}$. Based on the known lack of relationship between $\mathrm{mPaw}$ and $\mathrm{P}_{\mathrm{L}}$ during $\mathrm{CMV}$, we hypothesized that $\mathrm{P}_{\mathrm{L}}$ could not be predicted from $\mathrm{mPaw}$ during HFO.

\section{Subjects}

\section{METHODS}

All experimental procedures and protocols were approved by the Clinical Research Ethics Board at the University of British Columbia and Vancouver General Hospital (Vancouver, British Columbia). The trial was prospectively registered at ClinicalTrials.gov as NCT01321398.

${ }^{1}$ Division of Critical Care Medicine, Faculty of Medicine; ${ }^{2}$ School of Kinesiology, University of British Columbia, Vancouver, British Columbia;

${ }^{3}$ Department of Anesthesia, Critical Care and Pain Medicine, Beth Israel Deaconess Medical Center and Harvard Medical School, Boston,

Massachusetts, USA

Correspondence: Dr William R Henderson, Division of Critical Care Medicine, Faculty of Medicine, University of British Columbia, ICU2, JPPN 2nd Floor, Room 2438, 855 West 12th Avenue, Vancouver, British Columbia V5Z 1M9. Telephone 604-875-5949, fax 604-875-5957,

e-mail williamhenderson@shaw.ca 


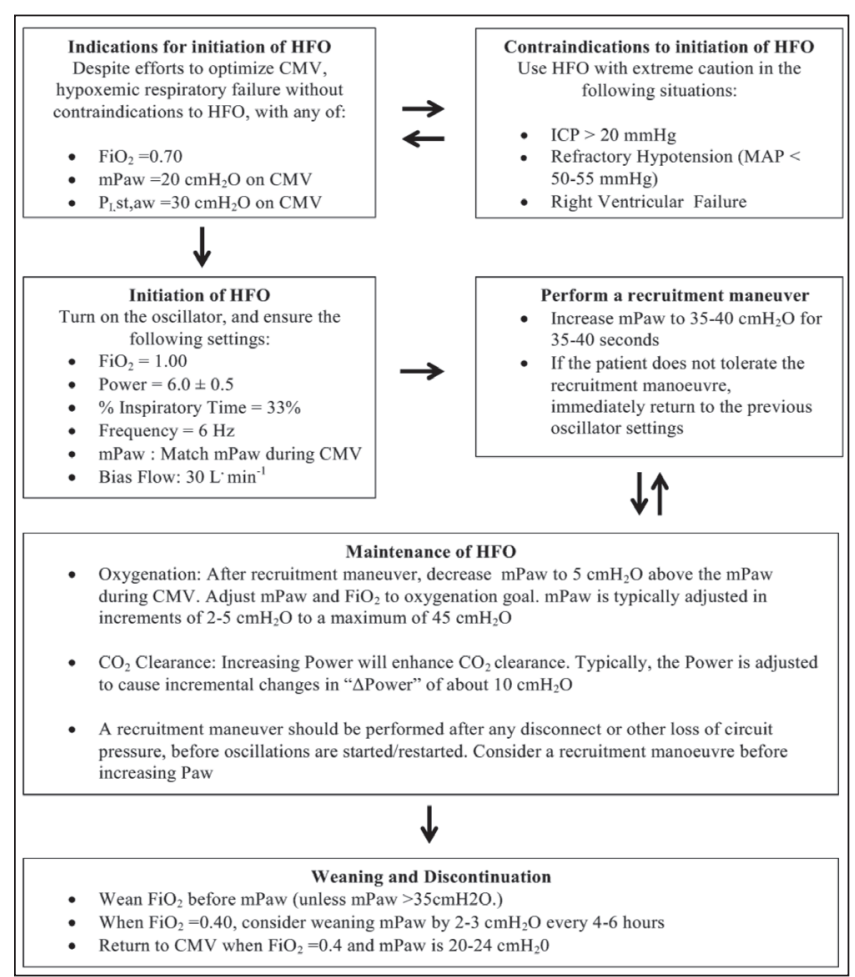

Figure 1) Clinical practice algorithm used to initiate and manage highfrequency oscillation (HFO) during observational period. CMV Conventional mechanical ventilation; ICP Intracranial pressure; $\mathrm{FiO}_{2}$ Fraction of inspired oxygen; MAP Mean arterial pressure; mPaw Mean airway pressure; $P_{L}$ Transpulmonary pressure

Patients were considered for the clinical use of HFO if they exhibited hypoxia, high mPaw or high Pplat refractory to optimized CMV and had no contraindications to HFO. Clinical management of HFO followed an explicit algorithm that prescribed mPaw adjustments, $\mathrm{FiO}_{2}$ adjustments and recruitment manoeuvres (Figure 1). All patients undergoing HFO between October 2010 and July 2011 were considered for the study and were included $(n=7)$ if they were receiving HFO for severe hypoxic respiratory failure or ARDS and were $\geq 19$ years of age. Patients receiving $\mathrm{HFO}$ were excluded from the present observational study if they had esophageal lesions, or had undergone esophageal surgery within the previous six months or experienced unstable cervical spine or cervical spinal cord injury. Informed written consent was obtained from the surrogate decision makers of all patients before the investigations. On average, the experimental data were recorded six days after the initiation of mechanical ventilation and two days after the initiation of HFO. Demographic and clinical information including age, cause of the acute lung injury, Acute Physiology and Chronic Health Evaluation (APACHE) II score, mean arterial blood pressure, central venous pressure, vasopressor dosing and pulmonary variables relevant to $\mathrm{HFO}$ such as bias flow, frequency, pressure amplitude as well as measured pressures ( $\mathrm{mPaw}, \mathrm{Pes}, \mathrm{Ppl}$ and $\mathrm{P}_{\mathrm{L}}$ ), were recorded.

\section{Experimental protocol}

All patients were ventilated using an adult $\mathrm{HFO}$ ventilator (Model 3100B, SensorMedics, USA). Patients were evaluated while supine. In all patients, an esophageal balloon catheter (No. 47-9005, Ackrad Laboratory, USA) was placed through the mouth into the esophagus to measure Pes. Catheter placement was performed by a study physician according to an adaptation of a previously detailed method (9) and was confirmed using a bedside chest radiograph. Positioning could not be assessed by traditional methods due to the ventilator mode and the patients' need for sedation. Positioning was considered to be correct when the tip of the catheter was visualized in the middle one-third

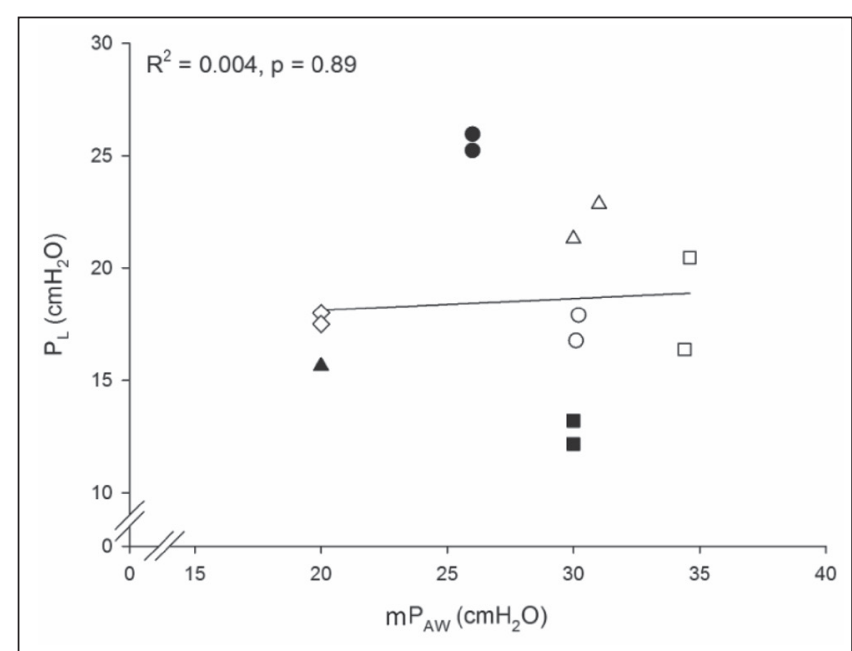

Figure 2) Relationship between transpulmonary pressure $\left(P_{I}\right)$ and mean airway pressure (mPaw). Hollow and solid circles, squares, diamonds and triangles are the observed pressures for individual patients at two time points. The single black triangle represents measurements at the two times points with identical values. The hollow diamonds represent the patient with hypoxia after lung transplantation. The solid line represents the values predicted by linear regression analysis. $R^{2}$ is the percent of variation of $P_{L}$ that is predicted by mPaw

of the distance from the thoracic inlet to the diaphragm. After placement was confirmed, air was evacuated from the balloon with a syringe and $1 \mathrm{~mL}$ of air was injected to partially inflate the balloon. Paw was obtained using a port at the side of the endotracheal tube connected to a differential transducer. Both pressures were measured using a calibrated piezoelectric pressure transducer (Raytech Instruments, Canada). All data were recorded continuously at $1000 \mathrm{~Hz}$ using a 16-channel analogue-to-digital data acquisition system (PowerLab/16SP model ML 795, ADI, USA) and stored on a computer for subsequent analysis (LabChart version 7.1.3, ADInstruments, USA). Both Paw measurements and $\mathrm{Ppl}$ estimates were recorded for $30 \mathrm{~s}$ after $1 \mathrm{~min}$ without spontaneous breathing or patient care-related movement. The arithmetic mean value of $\mathrm{Paw}$ and $\mathrm{Ppl}$ values for this 30 s period were used in the calculations. These measurements were repeated on the same day, $5 \mathrm{~min}$ after the original measurements. Pes was assumed to overestimate $\mathrm{Ppl}$ by $5 \mathrm{cmH}_{2} \mathrm{O}$ based on previously published estimates (10). The $\mathrm{P}_{\mathrm{L}}$ was calculated as the difference between mean $\mathrm{Ppl}$ and mPaw.

\section{Data analysis}

Data analysis was performed using Stata release 10 (StataCorp, USA). Linear regression was used to model the association between $\mathrm{P}_{\mathrm{L}}$ and mPaw (Figure 2), as well as the association of $\mathrm{P}_{\mathrm{L}}$ with central venous pressure and vasopressor dose. To account for the within-subject correlation, linear regression was performed on the mean $\mathrm{P}_{\mathrm{L}}$ and $\mathrm{mPaw}$ measurements. Statistical significance was defined at $\mathrm{P} \leq 0.05$.

\section{RESULTS}

The seven patients included in the study had ARDS secondary to pneumonia $(n=6)$ or acute complications of lung transplantation $(n=1)$ (Table 1). Two patients were co-enrolled in the Oscillation for ARDS Treated Early (OSCILLATE) trial (7). Before the study, the mean duration of $\mathrm{HFO}$ was one-half the mean duration of mechanical ventilation (Table 1). Severity of respiratory failure was confirmed with arterial blood gas values (Table 1). Two patients died in the intensive care unit and five patients survived to discharge from hospital. During the assessment period, the average mean arterial pressure was $79 \pm 10.6 \mathrm{mmHg}$, the average central venous pressure was $12 \pm 3.6 \mathrm{cmH}_{2} \mathrm{O}$ and four subjects required blood pressure support with intravenous 
norepinephrine (average dose $11.3 \pm 8.9 \mu \mathrm{g} / \mathrm{min}$ ). Esophageal balloon placement and measurements of Pes were achieved without complication in all seven patients. No patients underwent chemical paralysis immediately before or during the measurement period. The measurements provided mean values of Paw, Pes, estimated Ppl and calculated $\mathrm{P}_{\mathrm{L}}$ (Table 1). $\mathrm{P}_{\mathrm{L}}$ ranged from $12.2 \mathrm{cmH}_{2} \mathrm{O}$ to $25.2 \mathrm{cmH}_{2} \mathrm{O}$ and $\mathrm{Ppl}$ from $0.8 \mathrm{cmH}_{2} \mathrm{O}$ to $17.8 \mathrm{cmH}_{2} \mathrm{O}$. Linear regression showed no relationship between $\mathrm{P}_{\mathrm{L}}$ and $\mathrm{mPaw}(\beta=0.05$ [95\% CI -0.82 to 0.92]; $\mathrm{P}=0.89$ ) (Figure 2). Neither central venous pressure nor vasopressor dose displayed a significant relationship with $\mathrm{P}_{\mathrm{L}}(\mathrm{P}=0.073$ and $\mathrm{P}=0.97$, respectively).

\section{DISCUSSION}

While the use of esophageal manometry has been advocated for the estimation of Ppl during CMV for ARDS, we are the first to report on its use during HFO for adult ARDS. We have demonstrated that Pes can be measured by readily available methods during HFO, and our derived measurements support our hypothesis that $\mathrm{P}_{\mathrm{L}}$ cannot be predicted from mPaw. Collectively, our findings have meaningful implications for clinical care because $\mathrm{P}_{\mathrm{L}}$ has potentially competing effects in the management of ARDS. Specifically, appropriate $P_{L}$ is a key determinant of adequate oxygenation during mechanical ventilation (11); however, alveolar overdistension (due to high $\mathrm{P}_{\mathrm{L}}$ ) may be a primary factor in the generation of VILI $(12,13)$. Therefore, the accurate assessment of $\mathrm{Ppl}$ and $\mathrm{P}_{\mathrm{L}}$ may allow clinicians to maximize the beneficial effects of mechanical ventilation while minimizing iatrogenic harm.

Both $\mathrm{Ppl}$ and $\mathrm{P}_{\mathrm{L}}$ depend on the relationships between the elastance of the chest wall ( $\mathrm{Ew}_{\mathrm{w}}$ ), the lung $\left(\mathrm{E}_{\mathrm{L}}\right)$ and the total respiratory system (Ers, which is the sum of $\mathrm{Ew}$ and $\mathrm{E}_{\mathrm{L}}$ ), such that $\mathrm{Ppl}=\mathrm{Paw} \times \mathrm{Ew} / \mathrm{Ers}$ (14). In healthy individuals, $E_{w}$ and $E_{L}$ are approximately equal, such that the $\mathrm{Ew} / \mathrm{Ers}$ ratio has a value of approximately 0.5 . This ratio remains constant; therefore, it is reasonable to make assumptions about the value of $\mathrm{Ppl}$ based on Paw in healthy subjects. However, in ARDS, both Ew and $E_{\mathrm{L}}$ may vary considerably (both between subjects and within a subject if measured at different times during their illness), such that the ratio of Ew to Ers may vary from 0.2 to $0.8(14,15)$. The predominant cause of alterations in Ew during ARDS is abnormal abdominal pressure due to ascites, bowel distension or intra-abdominal blood (15). Additionally, pleural effusions, obesity and patient positioning may alter Ew $(16,17)$. Due to these causes of variation in Ew, $\mathrm{P}_{\mathrm{L}}$ may vary fourfold for a given $\mathrm{Paw}$ and it is exceedingly difficult to assume that $\mathrm{P}_{\mathrm{L}}$ may be inferred from Paw. While this is widely known during CMV, we are the first to demonstrate this during HFO in adult ARDS. During HFO, Ppl may vary with pleural fluid viscosity changes due to frequency-dependent oscillatory effects in excised dog lungs (18). While this phenomenon may occur in intact humans with lung injury, the impact of frequency-dependent pleural viscosity changes on Pes measurement and Ppl estimation in this situation is unclear.

Two recently published randomized clinical studies have compared best CMV versus $\mathrm{HFO}$ in adult patients with ARDS $(7,8)$. With a combined total of 1343 patients enrolled, the OSCILLATE and HighFrequency Oscillation for Acute Respiratory Distress Syndrome (OSCAR) trials found harm and equivalence, respectively, when HFO was compared with best practice CMV. Consistent with current guidelines (6), these two well-conducted trials initiated $\mathrm{HFO}$ with either a standard mPaw of $30 \mathrm{cmH}_{2} \mathrm{O}$ (OSCILLATE) or an mPaw of $5 \mathrm{cmH}_{2} \mathrm{O}$ above Pplat during CMV (OSCAR). Both studies titrated mPaw to arterial blood gases and neither estimated $\mathrm{Ppl}$ or $\mathrm{P}_{\mathrm{L}}$.

While the results of the OSCILLATE and OSCAR studies may reflect a true lack of benefit of HFO over CMV in ARDS, there are several points related to the underlying respiratory mechanics that should be considered when interpreting these data. Neither OSCILLATE nor OSCAR assessed Ew, $\mathrm{Ppl}$ or $\mathrm{P}_{\mathrm{L}}$ and were, therefore, unable to titrate $\mathrm{mPaw}$ and lung distension to any individual patient's respiratory mechanics. This raises the possibility that some patients (those with high $\mathrm{Ppl}$ and Ew) may have received lower distending
TABLE 1

Patient characteristics, ventilator settings and pressures in
patients treated with high-frequency oscillation for acute
respiratory distress syndrome

Age, years

Patients, men/women, $\mathrm{n} / \mathrm{n}$

$59 \pm 9$

Weight, $\mathrm{kg}$

$5 / 2$

APACHE II score

$80 \pm 40$

Duration of mechanical ventilation before study, days

$25 \pm 7$

Duration of high-frequency oscillation before study, days

$4 \pm 3$

$2 \pm 1$

Arterial blood gas values

$\mathrm{PaCO}_{2}, \mathrm{mmHg}$

$50 \pm 7$

$\mathrm{PaO}_{2}, \mathrm{mmHg}$

$80 \pm 10$

$\mathrm{FiO}_{2}$

$0.5 \pm 0.1$

$\mathrm{HCO}_{3}{ }^{-}, \mathrm{mEq} / \mathrm{L}$

$27 \pm 5$

$\mathrm{PaO}_{2} / \mathrm{FiO}_{2}$ ratio

$160 \pm 40$

High-frequency oscillation variables

Bias flow, L

$30 \pm 1$

Frequency, $\mathrm{Hz}$

$5 \pm 1$

Amplitude, $\mathrm{cmH}_{2} \mathrm{O}$

$75 \pm 10$

Measured and estimated pressures, $\mathrm{cmH}_{2} \mathrm{O}$

mPaw

$27 \pm 5$

Pes

$14 \pm 7$

$\mathrm{Ppl}$

$9 \pm 7$

$18 \pm 4$

Data presented as mean $\pm S D$ unless otherwise indicated. APACHE Acute Physiology and Chronic Health Evaluation; $\mathrm{FiO}_{2}$ Fraction of inspired oxygen; $\mathrm{HCO}_{3}{ }^{-}$Bicarbonate; $m P A W$ Mean airway pressure; $\mathrm{PaCO}_{2}$ Partial pressure of carbon dioxide; Pes Esophageal pressure; Ppl Pleural pressure; $P_{L}$ Transpulmonary mean airway pressure

pressures than necessary to prevent VILI and, thus, may have experienced relative hypoxia and atelectasis. Conversely, patients with very low $\mathrm{Ppl}$ and Ew could conceivably have received injuriously high levels of $\mathrm{P}_{\mathrm{L}}$. Either of these ' $\mathrm{P}_{\mathrm{L}}$-Paw mismatches' could have led to poorer outcomes than might have been apparent if $\mathrm{P}_{\mathrm{L}}$ have been assessed and mPaw titrated to individual patients' physiology. Ideally, these assessments of $\mathrm{Ppl}$ and $\mathrm{Ew}$ should be performed continuously or in a repeated fashion because $\mathrm{Ew}$ and $\mathrm{P}_{\mathrm{L}}$ may vary over time in the same patient.

In the present study, the mean $\mathrm{P}_{\mathrm{L}}$ was $<19 \mathrm{cmH}_{2} \mathrm{O}$ (Table 1 ), and the difference between the lowest and the highest value $\left(12.2 \mathrm{cmH}_{2} \mathrm{O}\right.$ and $25.2 \mathrm{cmH}_{2} \mathrm{O}$ ) was $>100 \%$. This raises the possibility that some of our patients safely tolerated higher mPaw, which may contribute to improved oxygenation and clinical outcomes. It is unknown whether similar $\mathrm{P}_{\mathrm{L}}$ values occurred in previous human $\mathrm{HFO}$ trials; however, this possibility may help to explain the negative mortality results demonstrated to date.

We estimated $\mathrm{Ppl}$ values during $\mathrm{HFO}$ to be from $0.8 \mathrm{cmH}_{2} \mathrm{O}$ to $17.8 \mathrm{cmH}_{2} \mathrm{O}$ (derived from Pes of $5.8 \mathrm{cmH}_{2} \mathrm{O}$ to $22.8 \mathrm{cmH}_{2} \mathrm{O}$ ), values similar to those found in previous measurements during CMV of ARDS patients (19). If known to treating clinicians, these values may prompt a change in mean airway settings during HFO. Additionally, the present study shows that $\mathrm{P}_{\mathrm{L}}$ cannot be estimated from mPaw during HFO.

\section{Limitations}

The present study had several limitations that must be recognized when considering the use of esophageal manometry and $\mathrm{P}_{\mathrm{L}}$ calculation during HFO. First, accurate measurement of Pes and estimation of $\mathrm{Ppl}$ is dependent on correct manometer placement. Due to patients' requirements for sedation, we were unable to perform voluntary 'sniff' testing of manometer placement. Similarly, we were precluded from performing passive occlusion tests because this would have required clamping of the endotracheal tube. Given the severe hypoxia that our patients experienced, this was believed to be an unreasonable 
intervention. We believe that chest $\mathrm{x}$-ray verification of placement provides a reasonable alternative strategy in this situation, and has been used in similar studies when conventional methods were not adequate (10).

Second, the validity of esophageal manometry in critically ill patients has been questioned: lung expansion in ARDS is heterogeneous and measured pressures may reflect local conditions present only in the tissue adjacent to the measurement site rather than whole lung conditions (20). Furthermore, the practice of subtracting $5 \mathrm{cmH}_{2} \mathrm{O}$ pressure from $\mathrm{Pes}$ to estimate $\mathrm{Ppl}$ may not be valid in all patients. Alternative methods include subtracting $2 \mathrm{cmH}_{2} \mathrm{O}$ to $3 \mathrm{cmH}_{2} \mathrm{O}$ (21) after measuring Pes following an end-expiratory occlusion or measuring Pes after a period of patient disconnection from the ventilator $(22,23)$. While we considered these latter two methods, in our opinion, they presented an unwarranted risk to the subjects. Despite the variability in Pes measurements introduced by these uncertainties, estimation of Ppl using esophageal manometry appears to be clinically useful $(10,19)$. In fact, a recent randomized trial showed an improvement in $\mathrm{PaO}_{2} / \mathrm{FiO}_{2}$ ratio of 88 $\mathrm{mmHg}$ in a treatment group guided by $\mathrm{Pes}$ than in a control group.

Third, our study may be limited by the assumption that $\mathrm{P}_{\mathrm{A}}$ and $\mathrm{Paw}$ are equivalent during $\mathrm{HFO}$, which may not be valid regionally or globally. Some investigators have demonstrated that $\mathrm{P}_{\mathrm{A}}$ may be lower or similar to $\mathrm{mPaw}$ and others have suggested that $\mathrm{P}_{\mathrm{A}}$ may exceed $\mathrm{mPaw}$ in some circumstances because of variations in ventilator settings, patient position, and variation between inspiratory and expiratory impedance (24-28). However, measuring $\mathrm{P}_{\mathrm{A}}$ directly is invasive and risky in patients with severe ARDS. Fourth, the small sample size in the present observational series may result in the study being underpowered.

Fourth, all patients enrolled in our study had ARDS due to a pulmonary cause as opposed to ARDS due to an 'extrapulmonary' cause (29). While our data are unable to clarify this issue, differences in lung

\section{REFERENCES}

1. Ranieri VM, Rubenfeld GD, Thompson BT, et al. Acute respiratory distress syndrome: The Berlin definition. JAMA 2012;307:2526-33.

2. Ventilation with lower tidal volumes as compared with traditional tidal volumes for acute lung injury and the acute respiratory distress syndrome. The Acute Respiratory Distress Syndrome Network. N Engl J Med 2000;342:1301-8.

3. Ritacca FV, Stewart TE. Clinical review: High-frequency oscillatory ventilation in adults - a review of the literature and practical applications. Crit Care 2003;7:385-90.

4. Hager DN, Fessler HE, Kaczka DW, et al. Tidal volume delivery during high-frequency oscillatory ventilation in adults with acute respiratory distress syndrome. Crit Care Med 2007;35:1522-9.

5. Goddon S, Fujino Y, Hromi JM, Kacmarek RM. Optimal mean airway pressure during high-frequency oscillation: Predicted by the pressure-volume curve. Anesthesiology 2001;94:862-9.

6. Fessler HE, Hess DR, Faarc RR. Respiratory controversies in the critical care setting. Does high-frequency ventilation offer benefits over conventional ventilation in adult patients with acute respiratory distress syndrome? Respir Care 2007;595-608.

7. Ferguson ND, Cook DJ, Guyatt GH, et al. High-frequency oscillation in early acute respiratory distress syndrome. N Engl J Med 2013;368:795-805.

8. Young D, Lamb S, Shah S, et al. High-frequency oscillation for acute respiratory distress syndrome. N Engl J Med 2013;368:806-13.

9. Milic-Emili J, Mead J, Turner J. Improved technique for estimating pleural pressure from esophageal balloons. J Appl Physiol 1964;19:207-11.

10. Loring SH, O'Donnell CR, Behazin N, et al. Esophageal pressures in acute lung injury: Do they represent artifact or useful information about transpulmonary pressure, chest wall mechanics, and lung stress? J Appl Physiol 2010;108:515-22.

11. Staffieri F, Stripoli T, De Monte V, et al. Physiological effects of an open lung ventilatory strategy titrated on elastance-derived endinspiratory transpulmonary pressure: Study in a pig model. Crit Care Med 2012;40:2124-31. recruitability and in the role of chest wall and lung elastances in pulmonary versus extrapulmonary ARDS may have altered the relationship between mPAW and $P_{L}$ if our patients had extrapulmonary causes of ARDS.

Finally, even if estimates of $\mathrm{Ppl}$ during $\mathrm{HFO}$ are accurate and reliable, it is unknown what the optimal $\mathrm{P}_{\mathrm{L}}$ should be. Although recommendations exist for limits of pressures measured at the airway (such as Pplat) during CMV, no similar guidelines are available for $\mathrm{P}_{\mathrm{L}}$ limits during either CMV or HFO. Due to the uncertainties of measurement, and the lack of evidence-based guidelines, we urge extreme caution in the use of $\mathrm{Ppl}$ and $\mathrm{P}_{\mathrm{L}}$ for the management of $\mathrm{mPaw}$ during $\mathrm{HFO}$.

\section{CONCLUSIONS}

The current study was the first to demonstrate that $\mathrm{P}_{\mathrm{L}}$ may be measured during $\mathrm{HFO}$ for adult ARDS and that it cannot be inferred from mPaw. The fact that $\mathrm{P}_{\mathrm{L}}$ could not be estimated from mPaw raises the possibility that poor outcomes in both clinical practice and trials of $\mathrm{HFO}$ may be due to individual differences in $\mathrm{P}_{\mathrm{L}}$ at the same $\mathrm{mPaw}$. Further study may confirm whether this supposition is correct and whether estimation of $\mathrm{P}_{\mathrm{L}}$ during $\mathrm{HFO}$ in adults would improve outcomes. While it is clear that $\mathrm{mPaw}$ is a poor surrogate for $\mathrm{P}_{\mathrm{L}}$, we caution clinicians in the use of $\mathrm{Ppl}$ to estimate $\mathrm{P}_{\mathrm{L}}$ during $\mathrm{HFO}$ until further investigations have been performed.

ACKNOWLEDGEMENTS: WRH, PBD and AWS conceived, designed and collected data for the study. WRH and DEGG analyzed the data. All authors developed and edited the manuscript. The authors thank Denise Foster RN, Maureen Gardner RN and Suzie Logie RN for their assistance in data collection. They also thank Elly Trepman MD and Carl Richmond for editorial assistance.

12. Eichacker PQ, Gerstenberger EP, Banks SM, Cui X, Natanson C. Meta-analysis of acute lung injury and acute respiratory distress syndrome trials testing low tidal volumes. Am J Respir Crit Care Med 2002;166:1510-4.

13. Sarge T, Talmor D. Targeting transpulmonary pressure to prevent ventilator induced lung injury. Minerva Anestesiol 2009;75:293-9.

14. Gattinoni L, Chiumello D, Carlesso E, Valenza F. Bench-to-bedside review: Chest wall elastance in acute lung injury/acute respiratory distress syndrome patients. Crit Care 2004;8:350-5.

15. Gattinoni L, Pelosi P, Suter P. Acute respiratory distress syndrome caused by pulmonary and extrapulmonary disease. Different syndromes? Am J Respir Crit Care Med 1998;158:3-11.

16. Pelosi P, Gattinoni L. Acute respiratory distress syndrome of pulmonary and extra-pulmonary origin: Fancy or reality? Intensive Care Med 2001;27:457-60.

17. Pelosi P, Croci M, Ravagnan I, Vicardi P, Gattinoni L. Total respiratory system, lung, and chest wall mechanics in sedated-paralyzed postoperative morbidly obese patients. Chest 1996;109:144-51.

18. Suki B, Hantos Z. Viscoelastic properties of the visceral pleura and its contribution to lung impedance. Respir Physiol 1992;90:271-87.

19. Talmor D, Sarge T, Malhotra A, et al. Mechanical ventilation guided by esophageal pressure in acute lung injury. N Engl J Med 2008;359:2095-104.

20. De Chazal I, Hubmayr RD. Novel aspects of pulmonary mechanics in intensive care. Br J Anaesth 2003;91:81-91.

21. Ranieri VM, Giuliani R, Mascia L, et al. Chest wall and lung contribution to the elastic properties of the respiratory system in patients with chronic obstructive pulmonary disease. Eur Respir J 1996;9:1232-9.

22. Ranieri VM, Giuliani R, Cinnella G, et al. Physiologic effects of positive end-expiratory pressure in patients with chronic obstructive pulmonary disease during acute ventilatory failure and controlled mechanical ventilation. Am Rev Respir Dis 1993;147:5-13. 
23. Guérin C, Coussa ML, Eissa NT, et al. Lung and chest wall mechanics in mechanically ventilated COPD patients. J Appl Physiol 1993;74:1570-80.

24. Simon BA, Weinmann GG, Mitzner W. Mean airway pressure and alveolar pressure during high-frequency ventilation. J Appl Physiol 1984;57:1069-78.

25. Allen JL, Frantz ID III, Fredberg JJ. Heterogeneity of mean alveolar pressure during high-frequency oscillations. J Appl Physiol 1987;62:223-8.

26. McCulloch PR, Forkert PG, Froese AB. Lung volume maintenance prevents lung injury during high frequency oscillatory ventilation in surfactant-deficient rabbits. Am Rev Respir Dis 1988;137:1185-92.
27. Gerstmann DR, Fouke JM, Winter DC, Taylor AF, deLemos RA. Proximal, tracheal, and alveolar pressures during high-frequency oscillatory ventilation in a normal rabbit model.

Pediatric Res 1990;28:367-73.

28. Zobel G, Dacar D, Rödl S. Proximal and tracheal airway pressures during different modes of mechanical ventilation: An animal model study. Pediatr Pulmonol 1994;18:239-43.

29. Pelosi P, D'Onofrio D, Chiumello D, et al. Pulmonary and extrapulmonary acute respiratory distress syndrome are different. Eur Resp J 2003;22(Suppl 42):48s-56s. 


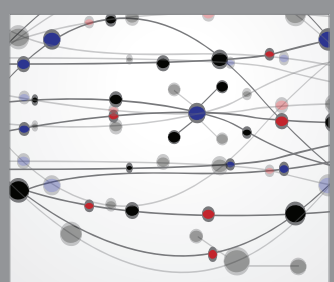

The Scientific World Journal
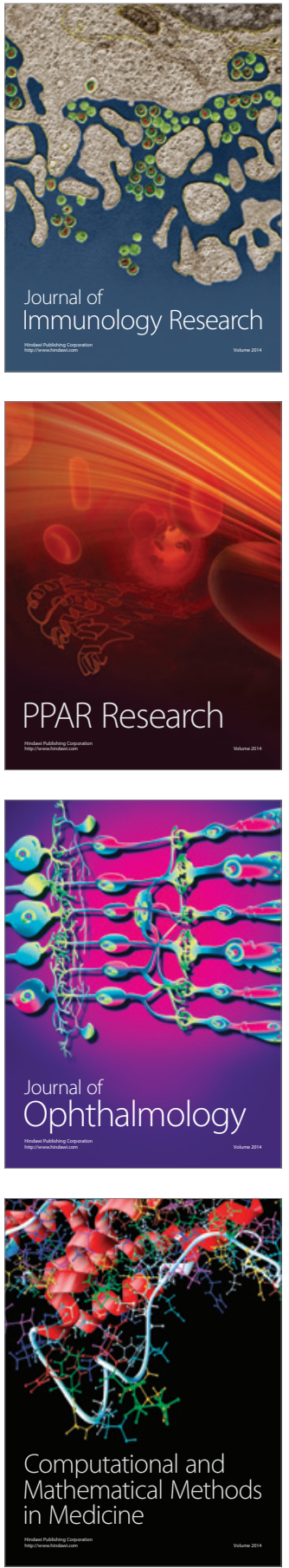

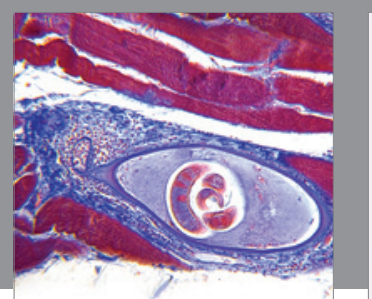

Gastroenterology Research and Practice

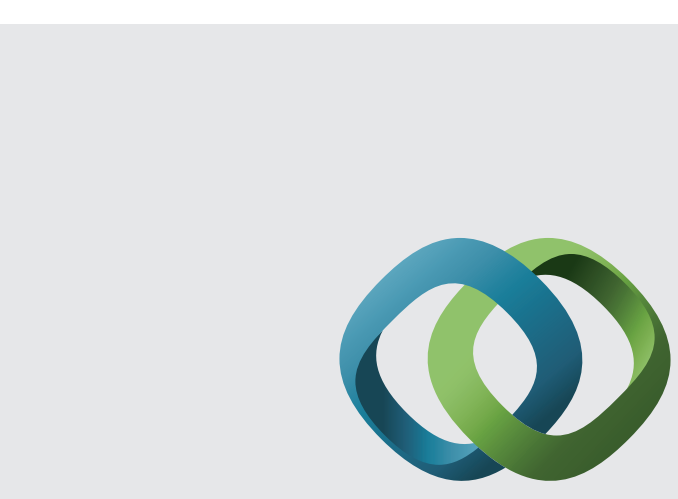

\section{Hindawi}

Submit your manuscripts at

http://www.hindawi.com
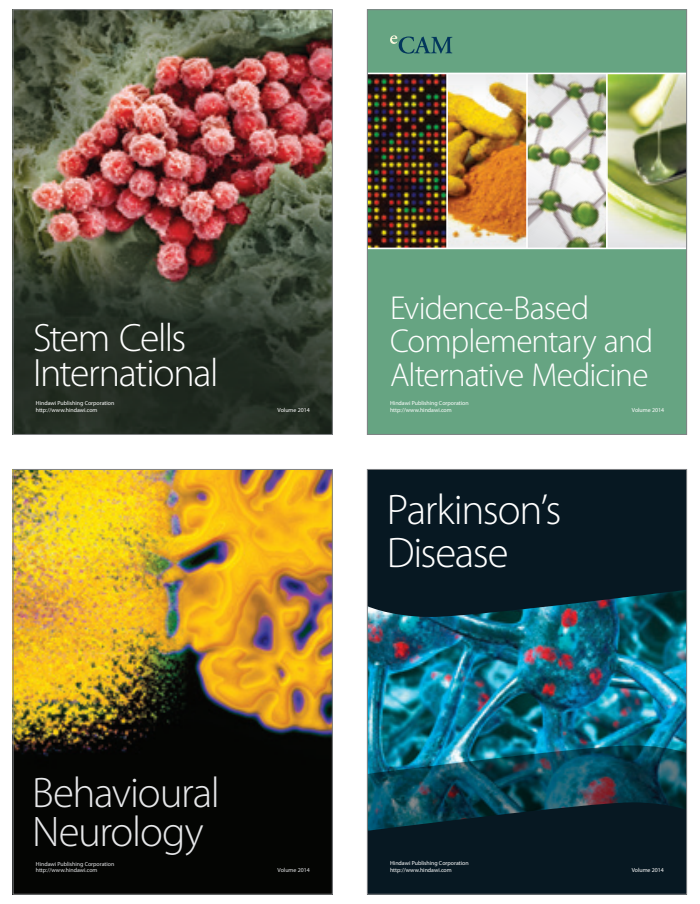
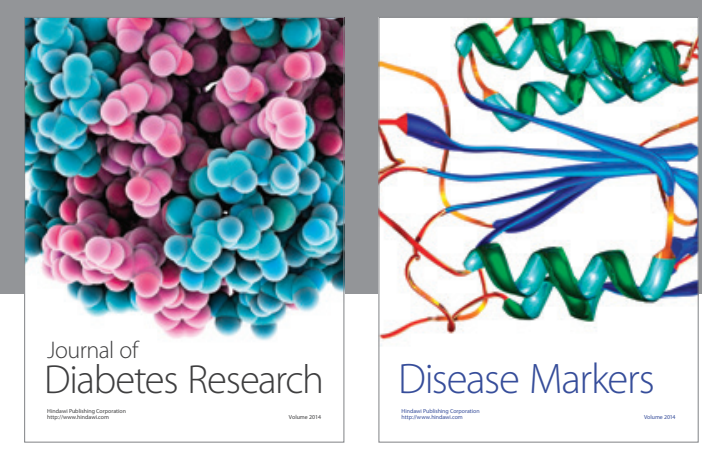

Disease Markers
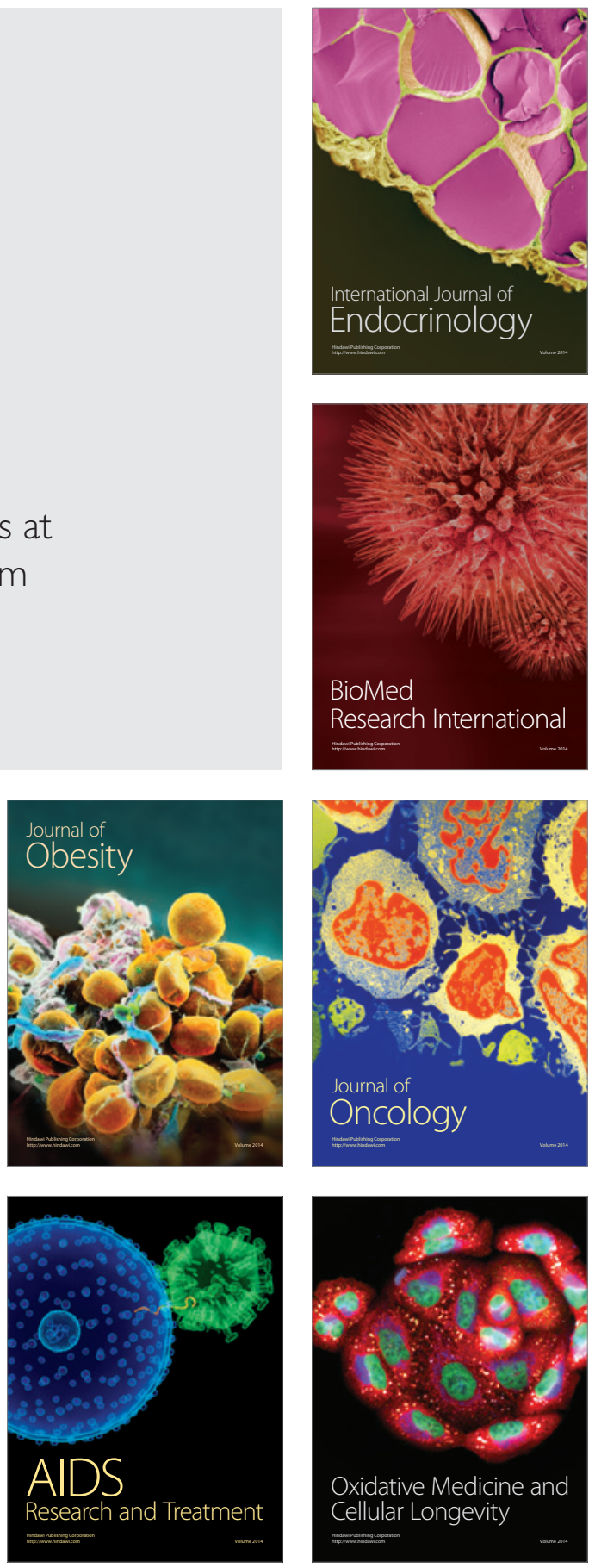